\title{
Hot-stage Microscopy - Direct Analysis in Real-Time Mass Spectrometry (HDM) as a novel tool for monitoring thermally-driven reactions on a small scale
}

\author{
Gage P. Ashton, Lindsay P. Harding, Gary Midgley, Gareth M.B. Parkes \\ Thermal Methods Research Unit, School of Applied Sciences, University of \\ Huddersfield, Queensgate, Huddersfield, UK
}

\section{Abstract}

There is a requirement for reliable real-time analytical tools for reaction monitoring to optimise chemical syntheses. We have developed a new technique which combines thermal analysis, digital microscopy and chemical identification using ambient ionisation mass spectrometry. We term this hot-stage microscopy-Direct Analysis in Real-Time mass spectrometry (HDM). The technique provides optical data as a function of temperature coupled with chemical characterisation of evolved species, including reactants, intermediates and products throughout the course of a reaction. In addition, only a few milligrams of sample are required with analyte detection down to the nanogram range. We demonstrate the benefits of HDM using a series of solventfree reactions. Our results confirm the suitability of the technique as the reactions studied follow the same pathways as published previously. The accurate temperature control achieved with HDM could also be used to assess the optimum temperature at which thermally-driven reactions can proceed efficiently.

\section{Keywords}

Direct Analysis in Real-Time Mass Spectrometry, Hot-stage microscopy, Reaction Monitoring, Green Chemistry. 


\section{Introduction}

Today the synthetic chemist has a large range of standard analytical methods to aid with reaction monitoring such as TLC [1], UV-VIS [2], FTIR [3] and NMR [4] commonly being used either offline or online. Conventional chromatography-mass spectrometry systems are less suited for reaction profiling as, although they combine separation with identification, it is not a real-time technique; sample preparation and at least some method development are usually required [5].

One particularly important area of synthesis is 'green chemistry' which is usually understood to mean a) ensuring the reaction is being driven in the most efficient and economical way and b) reducing or eliminating solvents and/or using ones which are less environmentally damaging [6]. Reaction monitoring methods can play a pivotal role in developing green reactions by evaluating the formation of intermediates and side products [7].

Ambient ionisation mass spectrometry (AIMS) is a technique that has been developed to allow ionisation of samples in open air [8]. The benefits of the technique include reduced sample preparation and applicability to a wide range of sample types [9].

Direct Analysis in Real-Time mass spectrometry (DART-MS) is an ambient ionisation technique that uses a heated stream of metastable helium species directed at a sample in open air. Analytes are thermally desorbed and ionised before entering the mass spectrometer [10].

DART-MS has offered a rapid sampling technique for the synthetic chemist with numerous publications demonstrating the use of DART for reaction monitoring [11]. Several authors have reported the use of DART for offline reaction monitoring, typically relying on manual input from the user with an aliquot from the reaction mixture being introduced to the DART source at discrete time intervals [12]. However, Ray et al., 
have shown that current sample introduction methods may limit its efficacy as an online reaction monitoring tool [13]. This is further exacerbated by the lack of sample temperature representation produced by DART [14].

We have previously reported development of the hot-stage microscope Direct Analysis in Real-Time mass spectrometry system (HDM) and its application to the analysis of systems such as environmental microplastics and the thermal degradation of polymers [15-16]. The HDM comprises three main components as shown in Figure 1.

A small ceramic hot-stage provides precise temperature control of samples (typically a few mg) to within $\pm 0.1^{\circ} \mathrm{C}$, over a temperature range of 30 to $750{ }^{\circ} \mathrm{C}$. Heating rates between 0.1 and ca. $200{ }^{\circ} \mathrm{C} \mathrm{min}^{-1}$ are achievable. The integrated microscope allows visualisation of thermal events such as melting, reaction and decomposition. Images can be recorded either as videos or as a series of pictures taken at user-defined intervals (time or temperature). Colour information extracted from the images can be used to profile optical changes in the sample. The custom DART source ionises evolved analytes, as the mass spectrometer records mass information in real-time.

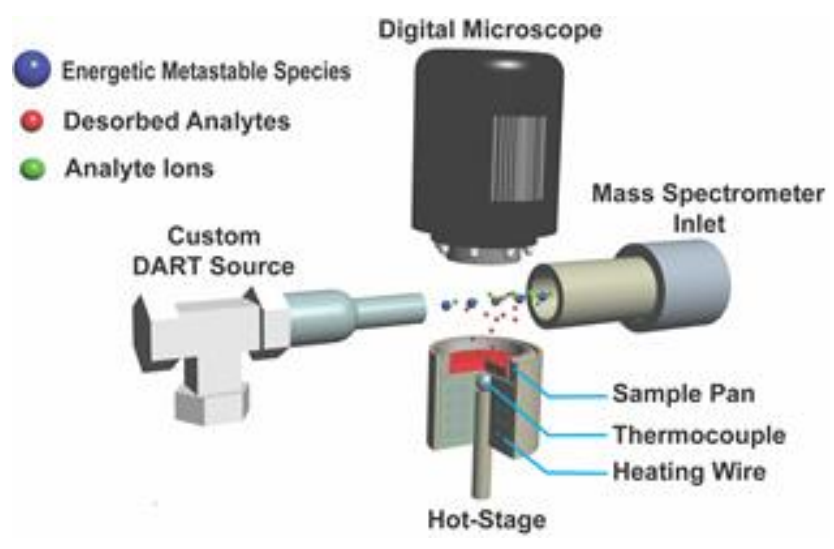

Figure. 1 Schematic diagram of the hot-stage microscope-DART-MS system

Herein we report the application of our novel system to monitoring green, solvent-free reactions, where no auxiliary solvents have been added save for those considered a 
reactant themselves. For this study all of the reactions were thermally-driven and benefitted from the precise temperature control of the HDM.

\section{Experimental}

\subsection{Instrumentation}

2.1.1 Hot-stage calibration procedure

The hot-stage was calibrated using thermal analysis calibration standards obtained from LGC. The metal calibration standards and their certified transition temperatures are indium (LGC2601, $\left.156.6^{\circ} \mathrm{C}\right)$, tin (LGC2609, $\left.231.9^{\circ} \mathrm{C}\right)$ and lead (LGC2608, 327.5 $\left.{ }^{\circ} \mathrm{C}\right)$. Typically, a flattened sample of the metal $(5-50 \mathrm{mg})$ is heated in a linear fashion and the melting point identified through reflectance colour changes (measured as changes in RGB values, $\triangle R G B$ ) as recorded by the digital microscope.

\subsubsection{General MS conditions}

Samples were analysed on a Bruker Esquire HCT ion trap mass spectrometer using a $\mathrm{m} / \mathrm{z}$ range of $100-2800$. Accumulation times of $200 \mathrm{~ms}$ were set with a Smart Target of 200,000 . The capillary voltage was set to $4 \mathrm{kV}$ and the source temperature was 300 ${ }^{\circ} \mathrm{C}$. The mass spectrometer was operated in either positive ion mode only, or alternating positive/negative ion mode as specified in section 2.2.

The mass spectrometer was calibrated according to the manufacturer's instructions. Mass and detector calibrations were carried out over a m/z range of 100-2700 using TuneMix (Agilent, Cheadle, UK) solution (diluted 1: $10 \mathrm{v} / \mathrm{v}$ in methanol).

\subsubsection{Data processing}

Full scan mass spectra were acquired for each experiment and averaged across the temperature range used. After examination of the spectra, ions of interest were selected for further processing. Extracted ion chromatograms (EICs) were plotted as 
a function of temperature for these selected ions. For clarity, these have been displayed in a normalised form in the Figures herein.

Red-green-blue pixel values (RGB values) were extracted from the optical data. These were plotted as a function of temperature either as a combined RGB value ( $\Sigma R G B)$ or as a change in $R G B$ value from the initial conditions at to ( $\triangle R G B)$.

\subsubsection{DSC}

Reaction products from syntheses of binol, 2,3-diphenylquinoxaline and tetraphenylpyrazine were analysed using a Mettler Toledo 822e differential scanning calorimeter (DSC). A sample (ca. $5 \mathrm{mg}$ ) was placed into an aluminium pan (ME-28331) and heated under an atmosphere of nitrogen at a rate of $5{ }^{\circ} \mathrm{C} \min ^{-1}$ between $30{ }^{\circ} \mathrm{C}$ and approximately $50^{\circ} \mathrm{C}$ above the expected melting point of each compound.

\subsubsection{NMR}

Proton NMR spectra of the reaction products from syntheses of binol and 2,3diphenylquinoxaline were analysed in $\mathrm{CDCl}_{3}$ using a Bruker AVIII $400 \mathrm{MHz}$ spectrometer. Data were processed using Bruker Topspin 4.0 software.

\subsubsection{Mass spectrometry (GC-MS and ESI-MS)}

Reaction products from syntheses of binol, 2,3-diphenylquinoxaline, 2phenylbenzimidazole and tetraphenylpyrazine were dissolved (methanol or THF) and injections $(1 \mu \mathrm{l})$ were made directly into a GC-MS system. The GC-MS system comprised an Agilent gas chromatograph (6890N) coupled to an Agilent 5975B mass spectrometer. A HP-5MS column was used for all samples using a carrier gas of helium (85 psi). Chromatograms were obtained using a linear heating rate of $25^{\circ} \mathrm{C}$ $\min ^{-1}$ from 100 to $275^{\circ} \mathrm{C}$, followed by a one minute isothermal period at the upper temperature. All data were processed using Agilent's Chemstation software (version E.02.02.1431). 
ESI-MS data were obtained for a sample of 1,4-bis(benzoimidazolyl)benzene following a work up and extraction into methanol. Accurate mass data were obtained by flowing the dissolved sample $(180 \mu \mathrm{l} / \mathrm{hr})$ into a Bruker Q-ToF mass spectrometer. A scan range of 50 to $800 \mathrm{~m} / \mathrm{z}$ was used. The capillary voltage was set to $4.5 \mathrm{kV}$ and the source temperature was $250^{\circ} \mathrm{C}$. The mass spectrometer was operated in positive ion mode only.

\subsection{Reactions}

Five reaction systems were selected to demonstrate the scope of HDM for reaction monitoring using two different types of reaction: solid-solid and solid-liquid.

\subsection{1 [1,1'-Binaphthalene]-2,2'-diol (binol)}

Racemic [1,1'-Binaphthalene]-2,2'-diol (commonly known as binol) can be produced by the oxidative coupling of 2-naphthol. This solid-solid reaction is known as the Scholl reaction [17], and is an important synthetic reaction used for forming carbon-carbon bonds within substituted aromatic rings primarily belonging to the phenol and naphthol families [18].

2-Naphthol (8 mg , $55.5 \mu \mathrm{mol}$, Aldrich 98\%) and iron (III) chloride hexahydrate (30 mg, $111 \mu \mathrm{mol}$, Acros 98\%) were lightly ground together before addition to the sample pan. The stage was heated at $1^{\circ} \mathrm{C} \min ^{-1}$ from 30 to $250{ }^{\circ} \mathrm{C}$. Full scan mass spectra were acquired in positive ion mode.

The composition of the product was confirmed using the ${ }^{1} \mathrm{H}$ NMR spectrum. $\delta_{\mathrm{H}}(400 \mathrm{MHz}$; CDCl 3 ; Me4Si) $5.057(2 \mathrm{H}, \mathrm{s},-\mathrm{OH}), 7.181(2 \mathrm{H}, \mathrm{d}, \mathrm{Ar}-H), 7.326(2 \mathrm{H}, \mathrm{td}, \mathrm{Ar}-$ $H), 7.387(4 \mathrm{H}, \mathrm{td}, \mathrm{Ar}-H), 7.412(2 \mathrm{H}, \mathrm{d}, \mathrm{Ar}-H), 7.920(2 \mathrm{H}, \mathrm{d}, \operatorname{Ar}-H), 8.002(2 \mathrm{H}, \mathrm{d}, \mathrm{Ar}-H)$. Figure S3 shows the DSC trace of the product. A sharp melt is observed at $\mathrm{T}_{\text {onset }}=$ $216.2^{\circ} \mathrm{C}$, agreeing closely with literature ranges published between 215 and $217^{\circ} \mathrm{C}$ [19]. 


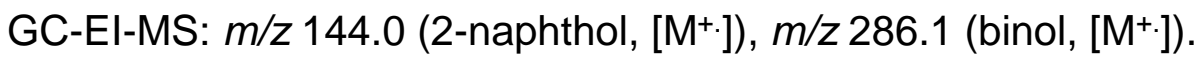

\subsubsection{2,3-Diphenylquinoxaline}

The solid-solid melt reaction between 1,2-diaminobenzene and benzil to form 2,3diphenylquinoxaline proceeds via a double condensation reaction to form a heterocyclic ring [20].

Equimolar amounts of 1,2-diaminobenzene (10.8 mg, $100 \mu \mathrm{mol}$, Aldrich 98\%) and benzil ( $21 \mathrm{mg}, 100 \mu \mathrm{mol}$, Aldrich 98+\%) were mixed by light grinding before addition to the analysis pan.

A linear temperature program of $5^{\circ} \mathrm{C} \mathrm{min}-1$ between 30 and $300{ }^{\circ} \mathrm{C}$ was used. The mass spectrometer was operated in positive ion mode.

The composition of the product was confirmed using the ${ }^{1} \mathrm{H}$ NMR spectrum.

$\delta_{\mathrm{H}}\left(400 \mathrm{MHz} ; \mathrm{CDCl}_{3}\right.$; Me $\left.4 \mathrm{Si}\right) 7.379(6 \mathrm{H}, \mathrm{m}, \mathrm{Ph}-H), 7.541(4 \mathrm{H}, \mathrm{dd}, \mathrm{Ph}-H), 7.807$ (2H, m, $\operatorname{Ar}-H), 8.211(2 H, m, \operatorname{Ar}-H)$.

The melting point of the product was determined using DSC and was found to be 125.6 ${ }^{\circ} \mathrm{C}$ (lit. 123-124 $\left.{ }^{\circ} \mathrm{C}\right)$ [21].

GC-EI-MS: m/z 282.1 (2,3-diphenylquinoxaline, [M+']).

\subsubsection{2-Phenylbenzimidazole}

This compound is commonly produced using Phillips' benzimidazole synthesis [22]. A modified form of this reaction was used here, in the absence of solvent. The reaction proceeds directly between liquid benzaldehyde and solid 1,2-diaminobenzene.

Benzaldehyde (20.4 $\mu \mathrm{L}, 200 \mu \mathrm{mol}$, Aldrich 98\%) was deposited onto 1,2diaminobenzene (21.6 mg, $200 \mu \mathrm{mol}$, Aldrich 98\%) in the reaction pan. A linear heating rate of $5^{\circ} \mathrm{C}$ min-1 $^{-1}$ was used between 30 and $300^{\circ} \mathrm{C}$. A second experiment was carried out using benzaldehyde in excess. The mass spectrometer was operated in positive ion mode only. 
GC-El-MS: m/z 194.1 (2-phenylbenzimidazole, [[M+']), m/z 284.1 (1-benzyl-2phenylbenzimidazole, $\left.\left[\mathrm{M}^{+\cdot}\right]\right)$.

\subsubsection{1,4-bis(benzoimidazolyl)benzene}

This compound is made via an analogous, but more complex, reaction to that described in section 2.2.3 where the benzaldehyde is replaced by terephthalaldehyde. In this case, both reactants are in the solid state [23].

1,2-Diaminobenzene (21.6 mg, $200 \mu \mathrm{mol}$, Aldrich 98\%) and terephthalaldehyde (benzene-1,4-dicarboxaldehyde, $13.4 \mathrm{mg}, 100 \mu \mathrm{mol}$, Aldrich 98\%) were layered side by side in the reaction pan. A linear heating rate of $5{ }^{\circ} \mathrm{C} \min ^{-1}$ was applied to the sample between 30 and $350{ }^{\circ} \mathrm{C}$. All resulting mass spectra were recorded in alternating positive/negative ion mode.

ESI-MS: $m / z \quad 311.1$ (1,4-bis(benzoimidazolyl)benzene, $\left.[\mathrm{M}+\mathrm{H}]^{+}\right)$; accurate mass 311.1281, calc. 311.1291, error -3.21 ppm.

\subsubsection{Tetraphenylpyrazine}

The synthesis of tetraphenylpyrazine uses three solid components (benzoin, ammonium acetate and anhydrous zinc chloride) and relies on the liberation of ammonia (from the ammonium salt) to initiate the reaction [24].

Benzoin (10.5 mg, $50 \mu \mathrm{mol}$, Aldrich 98+\%), ammonium acetate (7.4 mg, $100 \mu \mathrm{mol}$, Aldrich $>98 \%$ ) and anhydrous zinc chloride $(0.6 \mathrm{mg}, 5 \mu \mathrm{mol}$, Aldrich $>98 \%$ ) were ground together prior to the addition to the sample pan. A linear heating rate of $5{ }^{\circ} \mathrm{C}$ $\min ^{-1}$ was applied to the sample between 30 and $350{ }^{\circ} \mathrm{C}$. The mass spectrometer was operated in positive ion mode.

The melting point of the product was determined using DSC and was found to be 246.9 ${ }^{\circ} \mathrm{C}$ (lit. $\left.249^{\circ} \mathrm{C}\right)$ [25].

GC-EI-MS: m/z 384.2 (tetraphenylpyrazine, $\left[\mathrm{M}^{+} \cdot\right]$ ). 


\section{Results and Discussion}

\section{1 [1,1'-Binaphthalene]-2,2'-diol (binol)}

The overall synthesis of binol shown in Scheme 1 is based on the existing literature; a more detailed pathway is shown in Scheme S1 in the ESI [26].<smiles>Oc1ccc2ccccc2c1</smiles>

2-Naphthol Chemical Formula: $\mathrm{C}_{10} \mathrm{H}_{8} \mathrm{O}$ Monoisotopic Mass: 144.06

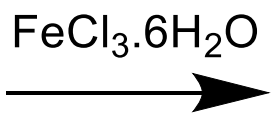<smiles>Oc1ccc2ccccc2c1-c1c(O)ccc2ccccc12</smiles>

Binol

Chemical Formula: $\mathrm{C}_{20} \mathrm{H}_{14} \mathrm{O}_{2}$ Monoisotopic Mass: 286.10

Scheme 1. Overall synthesis of binol from 2-naphthol and iron (III) chloride hexahydrate

The reaction has been extensively studied with primary focus on solvent-free synthesis which can be achieved with careful selection of reagents. Many of the literature methods evaluate the effect of the addition of various oxidants such as $\mathrm{FeCl}_{3} .6 \mathrm{H}_{2} \mathrm{O}$ [27], $\mathrm{MnO}_{2}$ [28] and $\mathrm{TiCl}_{4}[29]$ on the yield. Binol itself serves as a useful synthetic building block primarily used within the formation of organometallic catalysts [30] and as a chelating compound for fluorescence studies [31].

The reaction is induced by the oxidative iron (III) ion which complexes with the phenolic $\mathrm{OH}$ group and then removes an electron from the resonant carbanionic form of the 2naphthol. The iron (III) is itself reduced to iron (II). This electron removal yields a naphthol radical species based at the $\beta$-carbon. A radical pairing occurs to produce a diprotonated precursor to the binol product. Finally, two protons are lost yielding the final racemic binol product. Although many authors [26,32] claim that this reaction is a 
solid-solid reaction it is often neglected that ferric chloride hexahydrate dissolves in its waters of crystallisation at $\mathrm{ca} .37^{\circ} \mathrm{C}$ [33], so slight heating results in a heterogeneous state reaction.

Results of an experiment using a linear heating programme at $1{ }^{\circ} \mathrm{C} \mathrm{min}-1$ from 30 to $250{ }^{\circ} \mathrm{C}$ are shown in Fig 2. Fig. 2(ii) shows an average mass spectrum over the experiment. It indicates that the product, binol, at $\mathrm{m} / \mathrm{z} 286$ dominates with only trace amounts of thermal rearrangement products observed. No reactive intermediates were detected.
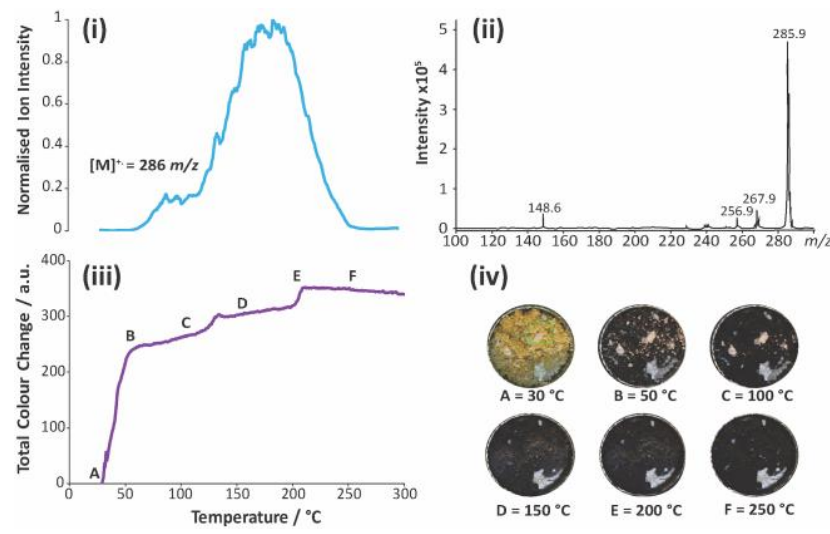

(iv)

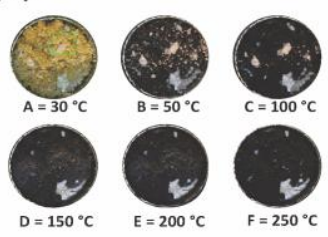

Figure 2. Synthesis of binol. (i) Extracted ion chromatogram of the binol product, with $\mathrm{m} / \mathrm{z} 286$, as a function of temperature; (ii) average mass spectrum over the full reaction period; (iii) $\triangle R G B$ profile; (iv) micrographs.

Figure 2(i) shows the formation of binol (demonstrated by the EIC of the molecular ion of binol at $m / z 286$ ) as a function of temperature. The profile shows a series of key steps. Nothing is observed until above $70{ }^{\circ} \mathrm{C}$ when there is the first indication that product is being formed. A plateau in the profile is shown from ca. 90 to $120^{\circ} \mathrm{C}$ which is tentatively attributed towards a steady state condition where the rate of product formation is matched by the rate of loss through thermal desorption. The rise in binol shown from $120^{\circ} \mathrm{C}$ can be directly correlated to the melting of the 2-naphthol reactant, at this moment the reaction rate significantly increases due to more intimate mixing between liquid reactant and the iron (III) chloride hexahydrate. Product is continuously 
evolved up until $185^{\circ} \mathrm{C}$ after which the decline in signal is assigned to the depletion of the product.

For this reaction, the optical component of HDM yields very useful complimentary data to the EIC profile. Figure 2(iii) shows the $\triangle R G B$ colour profile of the reaction as a function of temperature.

Micrographs of the reaction at a range of temperatures are shown in Fig. 2(iv). The most striking change is between images $A$ and $B$ going from a light yellow to a dark brown attributed to the release of water of crystallisation from iron (III) chloride hexahydrate around $37^{\circ} \mathrm{C}$. The dark colour itself most likely has two components, the actual 'wetting' of the 2-naphthol and also from the iron-naphthol complex that is known to be formed. This dark brown colour is used as a common indicator as a 'wet test' to show the presence of enols of which phenol and naphthol based compounds are an example [32].

The melting of the 2-naphthol and the rapid onset of product formation are clearly observable in both the colour profile and micrographs. Images $C$ and $D$ show a clear difference, the beige coloured spots of the 2-naphthol disappear during the melting and the colour profile shows a corresponding step change in RGB of 30 a.u. A final event relates to the melting of the binol product revealed by another step change in colour between 200 and $216{ }^{\circ} \mathrm{C}$ which correlates to the known melting point of the product.

Micrographs $\mathrm{E}$ and $\mathrm{F}$ show a very gradual change between brown and black as the product melts; although difficult to observe with the human eye, this is discernible on the $\triangle R G B$ trace.

Confirmatory studies were carried out using DSC and NMR on products obtained from the reaction on a larger scale. Figure S2 shows the NMR spectrum of the binol product 
(the inset shows an expansion of the aromatic region) which is in good agreement with the literature [34].

Figure S3 shows the DSC trace from analysis of the binol reaction product. A sharp melt is observed at $\mathrm{T}_{\text {onset }}=216.2^{\circ} \mathrm{C}$, agreeing closely with literature ranges published between 215 and $217^{\circ} \mathrm{C}[19]$.

Figure S4 shows the GC chromatogram and associated mass spectra of the starting material and binol product. lons are observed at $m / z 144.0$ (2-naphthol, $\left.\left[\mathrm{M}^{+} \cdot\right]\right)$, and $m / z$ 286.1 (binol, $\left[\mathrm{M}^{+\cdot}\right]$ ).

\subsection{2,3-Diphenylquinoxaline}

HDM was used to monitor the melt reaction between benzil and 1,2-diaminobenzene to form 2,3-diphenylquinoxaline. The overall reaction is outlined in Scheme 2; it is essentially a double dehydration condensation reaction forming an aromatic heterocyclic pyrazine ring.<smiles>Nc1ccccc1N</smiles>

1,2-Diaminobenzene Chemical Formula: $\mathrm{C}_{6} \mathrm{H}_{8} \mathrm{~N}_{2}$ Monoisotopic Mass: 108.07

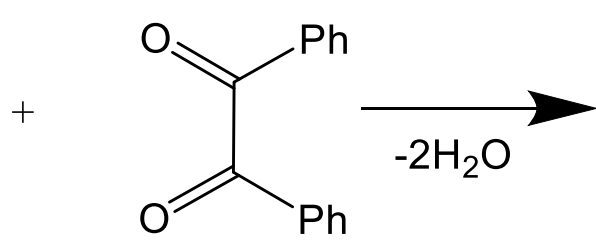

Benzil Chemical Formula: $\mathrm{C}_{14} \mathrm{H}_{10} \mathrm{O}_{2}$ Monoisotopic Mass: 210.07<smiles>c1ccc(-c2nc3ccccc3nc2-c2ccccc2)cc1</smiles>

2,3-Diphenylquinoxaline Chemical Formula: $\mathrm{C}_{20} \mathrm{H}_{14} \mathrm{~N}_{2}$ Monoisotopic Mass: 282.12

Scheme 2. Overall reaction between 1,2-diaminobenzene and benzil yielding 2,3diphenylquinoxaline.

Scheme S5 shows the proposed mechanistic pathway based on the existing literature [35]. Mamedov proposes that an amine group of 1,2-diaminobenzene attacks a carbonyl carbon of benzil, followed by proton transfer and dehydration. The final condensation is intramolecular, with the remaining amine group attacking the second carbonyl carbon, a process that is likely to be quick and driven by the aromatic 
stabilisation present in the final product. The water from the dehydration reactions is being driven off by the elevated temperatures curtailing, according to Le Chatelier's principle, possible reverse reactions.
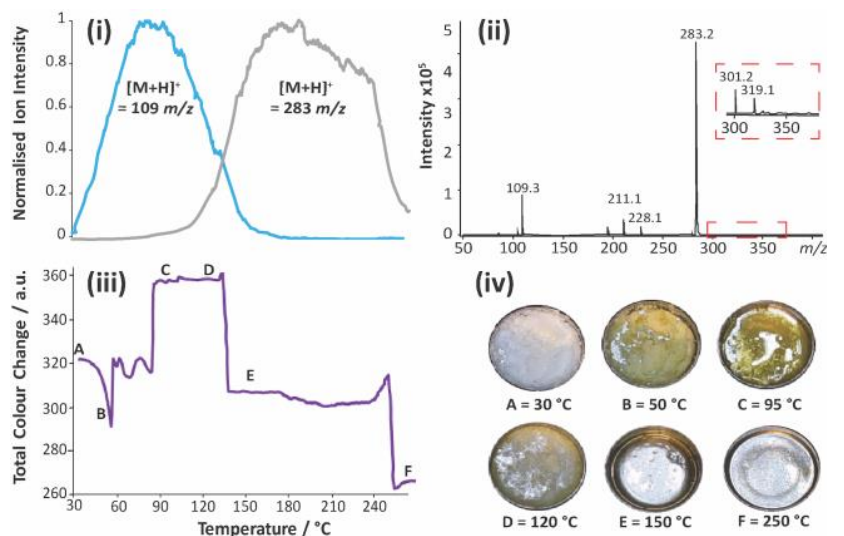

Figure 3. Synthesis of diphenylquinoxaline. (i) Extracted ion chromatograms of 1,2diaminobenzene $(\mathrm{m} / \mathrm{z} 109)$ and 2,3-diphenylquinoxaline $(\mathrm{m} / \mathrm{z} 283)$ as a function of temperature; (ii) average mass spectrum over the full reaction period (inset shows an expansion of the intermediate protonated molecular ion region); (iii) $\Sigma R G B$ profile; (iv) micrographs.

Figure 3(ii) shows the average mass spectrum for a linear heating experiment. Ions corresponding to both starting materials and the product can be seen $(1,2-$ diaminobenzene $\mathrm{m} / \mathrm{z} 109[\mathrm{M}+\mathrm{H}]^{+}$; benzil $\mathrm{m} / \mathrm{z} 211[\mathrm{M}+\mathrm{H}]^{+}$; 2,3-diphenylquinoxaline product $m / z 283[\mathrm{M}+\mathrm{H}]^{+}$). Reaction intermediates (Figure 3(ii), inset) were noted (see Scheme S5).

Figure 3(i) shows normalised EIC profiles of 1,2-diaminobenzene and 2,3diphenylquinoxaline. Benzil has been omitted as it undergoes suppression by the other components of the mixture. The signal from 1,2-diaminobenzene increases with temperature until a maximum at $90^{\circ} \mathrm{C}$. It then falls as the reactants are consumed and this coincides with the appearance of the product. After $180^{\circ} \mathrm{C}$ the rate of evolution of product falls as the material is evaporated.

Figures 3(iii) and (iv) show the $\Sigma$ RGB profile and selected micrographs for this reaction. At the onset of heating a colour change from white to yellow was seen 
(micrographs $\mathrm{A}$ and $\mathrm{B}$ ). Between 50 and $90{ }^{\circ} \mathrm{C}$ the reactants melt, exposing more of the metallic pan underneath $(\mathrm{C})$. By $120^{\circ} \mathrm{C}$, the reaction mixture appears to crystallise most likely due to supersaturation of the solution (D). A sharp step is shown in the colour profile at $130{ }^{\circ} \mathrm{C}$ as the reaction mixture melts $(\mathrm{E})$. The melt coincides with the maximum rate of evolution of the quinoxaline product in Figure 3(i). The colour profile remains relatively stable until $230{ }^{\circ} \mathrm{C}$ where the remaining product is lost, corresponding well with the loss of signal shown in Fig. 3(i).

Figure S6 shows the ${ }^{1} \mathrm{H}$ NMR spectrum of the final 2,3-diphenylquinoxaline product; the peaks appear consistent with the structure and in good agreement with the literature [36]. The spectrum shows no evidence of residual starting material (arylamine shifts between 3-5 ppm) and all peaks are assigned within the aromatic region. The DSC trace of the product is shown in Fig. S7. A sharp melt is observed at Tonset $=$ $125.6^{\circ} \mathrm{C}$, agreeing closely with literature ranges published between $124-126^{\circ} \mathrm{C}[21]$. The GC-MS chromatogram and mass spectrum are shown in Fig. S8. The product's molecular ion is seen at $m / z 282.1\left(\left[\mathrm{M}^{+}\right]\right)$.

\subsection{2-Phenylbenzimidazole}

Commonly, phenylbenzimidazoles are produced through reactions of primary amines and carbonyl-containing phenyl compounds such as benzaldehyde or benzoic acid as illustrated in Scheme 3.

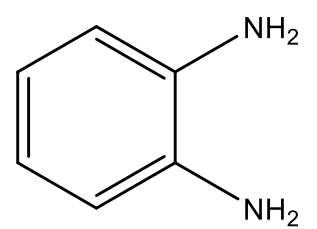

1,2-Diaminobenzene Chemical Formula: $\mathrm{C}_{6} \mathrm{H}_{8} \mathrm{~N}_{2}$ Monoisotopic Mass: 108.07

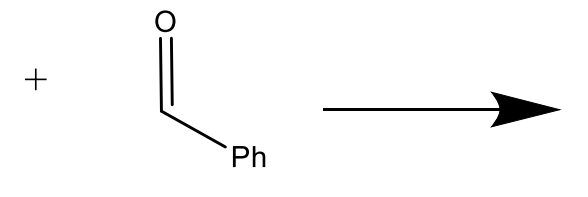

Benzaldehyde Chemical Formula: $\mathrm{C}_{7} \mathrm{H}_{6} \mathrm{O}$ Monoisotopic Mass: 106.04<smiles>c1ccc(-c2nc3ccccc3[nH]2)cc1</smiles>

2-Phenylbenzimidazole Chemical Formula: $\mathrm{C}_{13} \mathrm{H}_{10} \mathrm{~N}_{2}$ Monoisotopic Mass: 194.08

Scheme 3. Overall reaction between 1,2-diaminobenzene and benzaldehyde yielding substituted 2-phenylbenzimidazole. 
Scheme S9 shows a proposed mechanistic pathway based on existing literature [37]. The reaction can follow one of two routes, depending on the stoichiometry of the reactants [38]. According to Scheme S9 a 1:1 stoichiometry ideally would form 2phenylbenzimidazole directly. However, the final step in the formation of 2phenylbenzimidazole is oxidatively driven, therefore a reduced oxygen environment (as is the case in the ionisation region of the HDM) may allow the additional formation of product 2. This would occur through interaction with another molecule of benzaldehyde before the intramolecular ring closing of the highlighted intermediate.

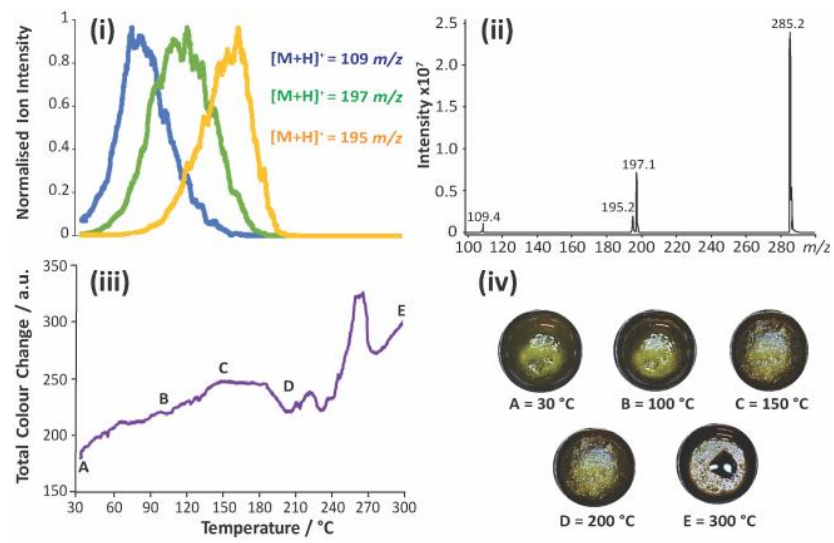

Figure 4. Synthesis of 2-phenylbenzimidazole. (i) Extracted ion chromatogram of 1,2diaminobenzene $(\mathrm{m} / \mathrm{z}$ 109), the intermediate (E)-2-benzylideneamine)aniline $(\mathrm{m} / \mathrm{z}$ $197)$ and 2-phenybenzimidazole $(\mathrm{m} / \mathrm{z} 195)$ as a function of temperature; (ii) average mass spectrum over the full reaction period; (iii) $\Sigma R G B$ profile; (iv) micrographs.

Figure 4(ii) shows the average mass spectrum for a $1: 1$ reaction between 1,2diaminobenzene and benzaldehyde. Under these conditions both possible products are observed. Figure 4(i) shows the normalised EICs for 1,2-diaminobenzene $(\mathrm{m} / \mathrm{z}$ 109, $\left.[\mathrm{M}+\mathrm{H}]^{+}\right)$, intermediate $\left((\mathrm{E})-2-\left(\right.\right.$ benzylideneamino)aniline, $\left.\mathrm{m} / \mathrm{z} 197,[\mathrm{M}+\mathrm{H}]^{+}\right)$and product (2-phenylbenzimidazole, $m / z 195,[\mathrm{M}+\mathrm{H}]^{+}$) which follow the expected profiles. Figures 4(iii) and (iv) show the $\Sigma$ RGB profile and selected micrographs for this reaction. The colour changes are less pronounced; however, the conversion from the liquid state to a semi-solid state is clearly apparent (micrographs A-C). The 
development of the semi-solid correlates well with the rise in the EIC of product 1. After $170{ }^{\circ} \mathrm{C}$ the sample darkens, a process linked to the decline of product 1 due to thermal decomposition which continues until a brown oil remains at the end of the experiment (D-E).

Figure 5 shows the results from an experiment using an excess of benzaldehyde. which does appear to increase the yield of the secondary product. Reactant and intermediate profiles follow closely the 1:1 example having a similar shape.
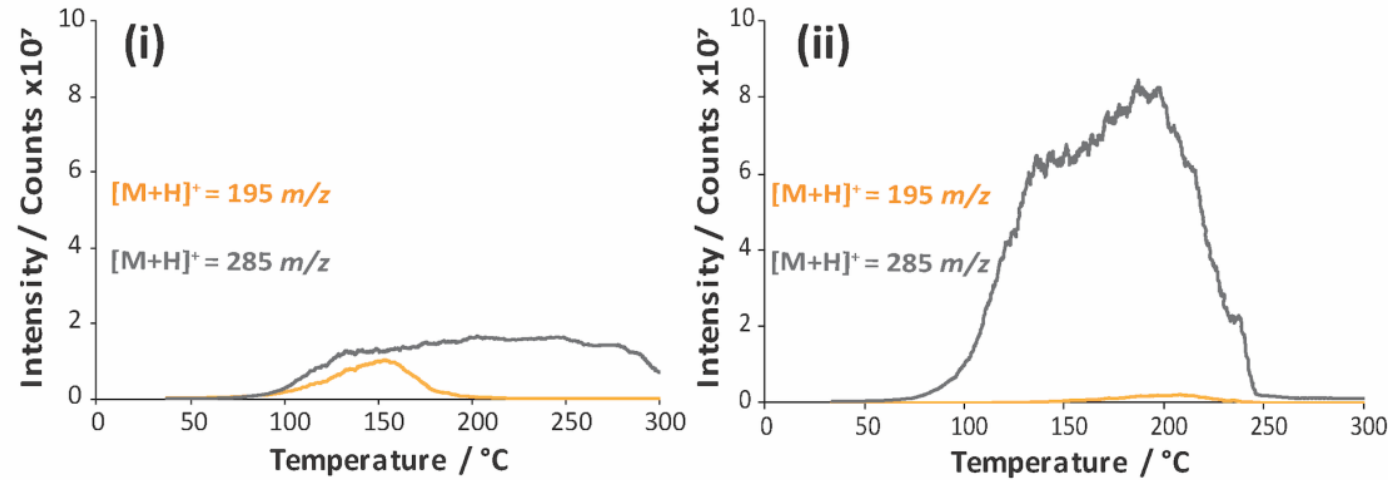

Figure 5. Extracted ion chromatograms for product $1(\mathrm{~m} / \mathrm{z} 195)$ and product $2(\mathrm{~m} / \mathrm{z}$ 285). (i) 1:1 stoichiometry; (ii) excess benzaldehyde.

Figure S10 shows the GC chromatogram and associated mass spectra of two reaction products. Molecular ions are observed at $m / z 194.1$ (2-phenylbenzimidazole, $\left[\mathrm{M}^{+\cdot}\right]$ ), and $m / z 284.1$ (product 2, $\left[\mathrm{M}^{+}\right]$).

\subsection{1,4-bis(benzoimidazolyl)benzene}

The overall reaction between 1,2-diaminobenzene and terephthalaldehyde to form 1,4-bis(benzoimidazolyl)benzene is shown in Scheme 4. 
<smiles>Nc1ccccc1N</smiles>

1,2-Diaminobenzene Chemical Formula: $\mathrm{C}_{6} \mathrm{H}_{8} \mathrm{~N}_{2}$ Monoisotopic Mass: 108.07

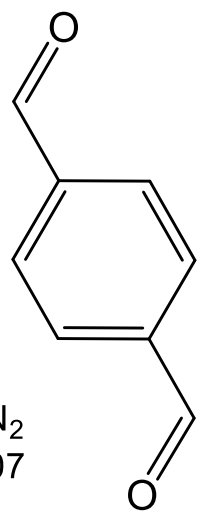

Terephthalaldehyde Chemical Formula: $\mathrm{C}_{8} \mathrm{H}_{6} \mathrm{O}_{2}$ Monoisotopic Mass: 134.04

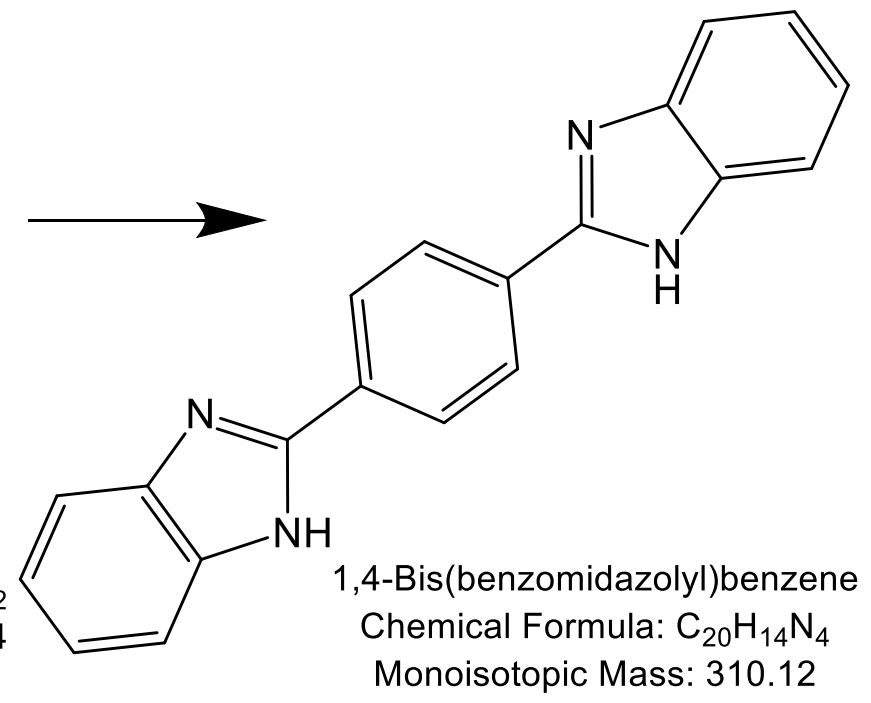

Scheme 4. Reaction overview for the synthesis of 1,4-bis(benzoimidazolyl)benzene This reaction is analogous to the previous experiment but using a solid dialdehyde.

The proposed reaction mechanism is outlined in Scheme S11 and was based on the mechanism from the 2-phenylbenzimidazole example (Scheme 3). The mechanism has several key steps, nucleophilic attack between an amine and the aldehyde carbonyl, followed by imine formation via dehydration. A subsequent intramolecular reaction occurs forming a mono-substituted imidazole intermediate. The process is repeated at the remaining aldehyde, resulting in the formation of the final product.
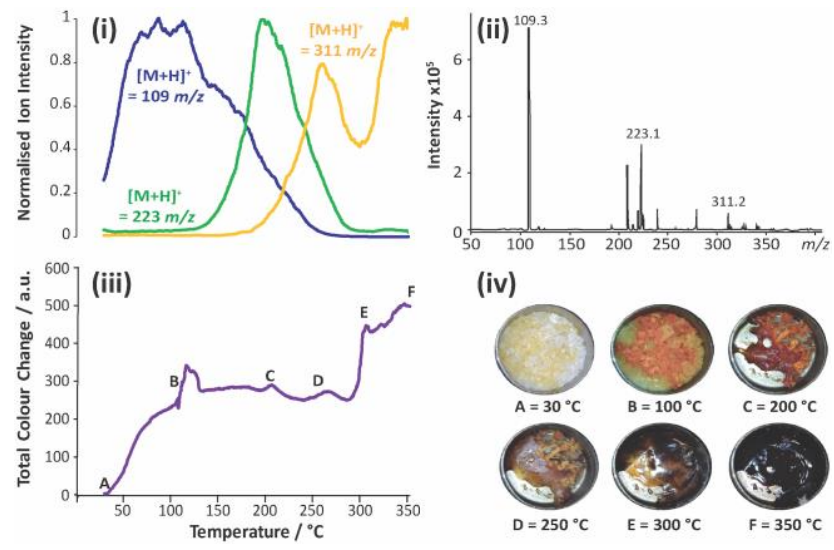

(iv)

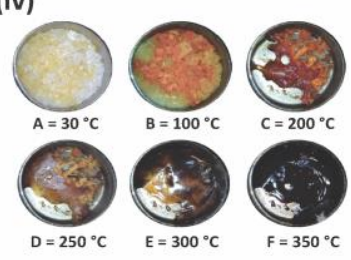

Figure 6. Synthesis of 1,4-bis(benzoimidazolyl)benzene. (i) Extracted ion chromatogram of 1,2-diaminobenzene $(\mathrm{m} / \mathrm{z} 109)$, the monosubstituted intermediate $(\mathrm{m} / \mathrm{z} 223)$ and the 1,4-bis(benzoimidazolyl)benzene product $(\mathrm{m} / \mathrm{z} 311)$ as a function of temperature; (ii) average mass spectrum over the full reaction period; (iii) $\triangle R G B$ profile; (iv) micrographs. 
Figure 6(ii) shows the average mass spectrum over the full duration of the reaction; the major reaction signals are marked. The three signals of interest are of the protonated molecular ions for 1,2-diaminobenzene $\left(m / z \quad 109[\mathrm{M}+\mathrm{H}]^{+}\right)$, the monosubstituted imidazole intermediate $\left(m / z \quad 223 \quad[M+H]^{+}\right)$and the 1,4bis(benzoimidazolyl)benzene product $\left(\mathrm{m} / z 311[\mathrm{M}+\mathrm{H}]^{+}\right)$. The EICs of these signals are displayed in Figure 6(i) which shows the normalised signals plotted as a function of temperature.

1,2-Diaminobenzene is detected from the onset of the experiment; around its melting point $\left(102-104^{\circ} \mathrm{C}\right)$ the signal declines and the intermediate starts to appear, followed by the product. The initial decline in product abundance between 250 and $300{ }^{\circ} \mathrm{C}$ is attributed to solidification of the mixture. Above $300{ }^{\circ} \mathrm{C}$ the mixture melts and the product signal increases until the end of the experiment at $350{ }^{\circ} \mathrm{C}$.

The micrographs in Figure 6(iv) show significant colour changes across the entire reaction. The melting of the reactant, 1,2-diaminobenzene, is evident around $100{ }^{\circ} \mathrm{C}$. The formation of the solid at $250{ }^{\circ} \mathrm{C}$ and its subsequent melting at $300^{\circ} \mathrm{C}$ can also be seen as a sharp increase in the RGB profile due to a change in reflectance (Fig. 6(iii)). Figure S12 shows the full ESI mass spectrum and an expansion of the molecular ion region from 310 to $315 \mathrm{~m} / \mathrm{z}$ for the 1,4-bis(benzoimidazolyl)benzene reaction product. The protonated molecular ion of 1,4-bis(benzoimidazolyl)benzene was observed $\mathrm{m} / \mathrm{z}$ $311.1281\left([\mathrm{M}+\mathrm{H}]^{+}\right)$.

\subsection{Tetraphenylpyrazine}

The synthesis of tetraphenylpyrazine uses solid components (benzoin, ammonium acetate and anhydrous zinc chloride) and relies on the liberation of ammonia (from the ammonium salt) to initiate the reaction as shown below in Scheme 5 . 
<smiles>O=C(c1ccccc1)C(O)c1ccccc1</smiles>

Benzoin

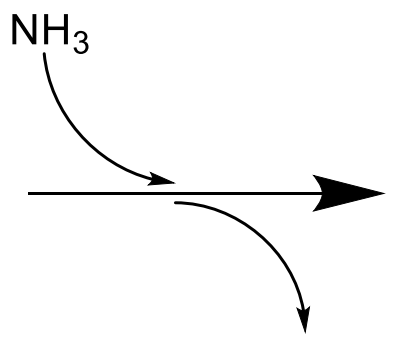

$\mathrm{H}_{2} \mathrm{O}$

Chemical Formula: $\mathrm{C}_{14} \mathrm{H}_{12} \mathrm{O}_{2}$

Monoisotopic Mass: 212.08<smiles>c1ccc(-c2nc(-c3ccccc3)c(-c3ccccc3)nc2-c2ccccc2)cc1</smiles>

Tetraphenylpyrazine Chemical Formula: $\mathrm{C}_{28} \mathrm{H}_{20} \mathrm{~N}_{2}$ Monoisotopic Mass: 384.16

Scheme 5. Overall reaction between ammonia and benzoin forming tetraphenylpyrazine.

Benzoin is commonly used as an organic building block finding particular use within pharmaceutical formulations [39].

In the following example, benzoin undergoes nucleophilic attack from ammonia liberated through the thermal decomposition of ammonium acetate, yielding ammonia and acetic acid. An aminol intermediate is formed which then undergoes dehydration yielding a Schiff base imine. The tautomeric amino-ketone form may then undergo self-cyclisation through a double dehydration. The final step relies on oxidation from the atmosphere to form the aromatic stabilised pyrazine ring. A proposed mechanism is shown in Scheme S13 based on existing pyrazine literature [24]. This is a particularly complex system due to the potential for side reactions.
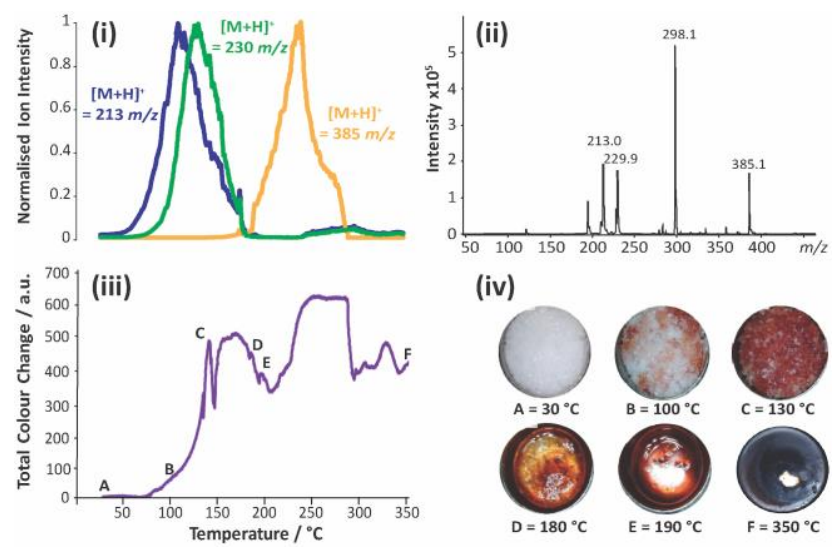

(iv)

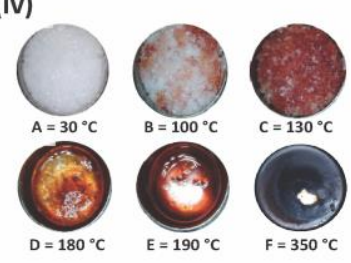

Figure 7. Synthesis of tetraphenylpyrazine. (i) Extracted ion chromatogram of benzoin $(\mathrm{m} / \mathrm{z} 213)$, the aminol intermediate $(\mathrm{m} / \mathrm{z} 230)$ and tetraphenylpyrazine $(\mathrm{m} / \mathrm{z} 385)$ as a 
function of temperature; (ii) average mass spectrum over the full reaction period; (iii) $\triangle R G B$ profile; (iv) micrographs.

Key ions are noted having direct relation to the tetraphenylpyrazine synthesis, along with several other ions most likely arising from side reactions.

Figure 7(ii) shows the average mass spectrum over the course of the reaction, the key ions being monitored are the protonated molecular ion of benzoin $\left(\mathrm{m} / z 213[\mathrm{M}+\mathrm{H}]^{+}\right)$, the protonated molecular ion of the aminol intermediate $\left(\mathrm{m} / \mathrm{z} 230[\mathrm{M}+\mathrm{H}]^{+}\right)$and finally the protonated molecular ion of tetraphenylpyrazine $\left(\mathrm{m} / \mathrm{z} 385[\mathrm{M}+\mathrm{H}]^{+}\right)$.

The base peak of the mass spectrum is an ion at $m / z 298$, this has been attributed to the product of a side reaction shown in Scheme 6. Early work performed by Leslie et al. noted the formation of quantitative yields of 2,4,5-triphenyloxazole along with tetraphenylpyrazine [40].<smiles>O=C(c1ccccc1)C(O)c1ccccc1</smiles>

Benzoin Chemical Formula: $\mathrm{C}_{14} \mathrm{H}_{12} \mathrm{O}_{2}$ Monoisotopic Mass: 212.08

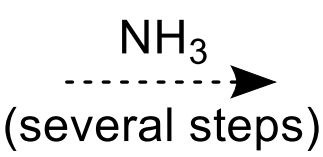<smiles>c1ccc(-c2nc(-c3ccccc3)c(-c3ccccc3)o2)cc1</smiles>

2,4,5-triphenyloxazole Chemical Formula: $\mathrm{C}_{21} \mathrm{H}_{15} \mathrm{NO}$ Monoisotopic Mass: 297.12

Scheme 6 . Side product formation during tetraphenylpyrazine reaction, proposed origin of the $298 \mathrm{~m} / \mathrm{z}$ signal.

Figure 7(i) shows selected EICs for the reaction of benzoin to form tetraphenylpyrazine via the aminol intermediate. The first stages of heating see the release of benzoin up to around $100{ }^{\circ} \mathrm{C}$. The maximum intensity of the protonated aminol intermediate is noted around $130^{\circ} \mathrm{C}$. Both benzoin and the aminol decline until $180^{\circ} \mathrm{C}$ when they are no longer discernible. Unlike other reactions discussed previously, the product signal 
does not begin to evolve until the apparent end of the intermediate signal, as opposed to during the decline of the intermediate.

Figure 7 (iv) shows micrographs from key points during the reaction. Micrograph $A$ shows the starting materials which are both white crystalline solids. Micrographs B and $\mathrm{C}$ show a gradual colour change with increasing temperature which we ascribe to formation of the aminol intermediate. Micrographs D-E show the red mixture begin to melt, a process which correlates well with the increase of the tetraphenylpyrazine ion intensity (Fig. 7(i)). The final micrograph $(F)$ shows the formation of a tar-like substance at high temperatures $\left(>250{ }^{\circ} \mathrm{C}\right)$. The EIC for the product ion declines sharply during this period.

The changes seen in the micrographs are mirrored in the RGB profile (Fig. 7(iii)). The change in colour from white to red is observed between 30 and $130{ }^{\circ} \mathrm{C}(\mathrm{A}-\mathrm{C})$. $\mathrm{A}$ possible reason for this colour change is due to a bathochromic shift caused by the reaction intermediates complexing with zinc ions [41].

Between 150 and $200^{\circ} \mathrm{C}$ the decrease in the RGB signal corresponds to the sample melting (D). The remaining colour profile indicates the onset of decomposition primarily within the $200-240{ }^{\circ} \mathrm{C}$ region. The final step at $280^{\circ} \mathrm{C}$ is related to a loss in liquid volume as the products begin to boil away at the elevated temperatures to leave a dark-coloured residue (F).

Figure $\mathrm{S} 14$ shows the DSC trace from analysis of the tetraphenylpyrazine reaction product. A melt is observed at $\mathrm{T}_{\text {onset }}=246.9^{\circ} \mathrm{C}$, close to the literature value of $249^{\circ} \mathrm{C}$ [25].

Figure S15 shows the GC chromatogram and associated mass spectra of the tetraphenylpyrazine reaction product. The products molecular ion is seen at $m / z 384.2$ (tetraphenylpyrazine, $\left[\mathrm{M}^{+}\right]$). 


\section{Conclusion}

HDM was successfully applied to the study of five thermally-driven, solvent-free reactions (solid-liquid and solid-solid). The products, intermediates and side-products observed were consistent with those proposed in the literature and their structures have been confirmed using other spectroscopic and thermal techniques.

We have demonstrated that HDM is a useful means of monitoring a wide range of reactions of relevance to green chemistry, being applicable to the study of organic reactions in a variety of physical states covering both heterogeneous and homogeneous syntheses. The combination of precise temperature control, real-time optical microscopy and mass spectrometry provides a unique insight into reaction processes not available with other techniques. Although the experiments reported herein have used linear heating programs, more complex temperature profiles, involving heating, cooling and isothermal stages, are possible.

The interpretation of complex mass spectral profiles can be aided by the optical data (micrographs and colour profiles) that the HDM provides. Typically, only a few milligrams of material are required to evaluate a reaction which means that the technique is an efficient way to optimise reaction conditions. The accurate temperature control achieved with HDM could also be used to assess the optimum temperature at which thermally-driven reactions can proceed efficiently.

\section{References}

\footnotetext{
${ }^{1}$ B. Hemmateenejad, M. Akhond, Z. Mohammadpour and N. Mobaraki, Quantitative monitoring of the progress of organic reactions using multivariate image analysis-thin layer chromatography (MIA-TLC) method, Analytical Methods, 2012, 4, 933-939.

2 L. R. Knöpke, N. Nemati, A. Köckritz, A. Brückner and U. Bentrup, Reaction Monitoring of Heterogeneously Catalyzed Hydrogenation of Imines by Coupled ATR-FTIR, UV/Vis, and Raman Spectroscopy, ChemCatChem, 2010, 2, 273-280.
} 
${ }^{3}$ E. J. Rogers and S. F. Kudlin, Infrared spectroscopy as a tool to monitor the reactions of alcohols and aldehydes with phenyl N-bromoketimine, Microchemical Journal, 1979, 24, 426-430.

${ }^{4}$ D. A. Foley, A. L. Dunn and M. T. Zell, Reaction monitoring using online vs tube NMR spectroscopy: seriously different results, Magn. Reson. Chem., 2016, 54, 451-456.

5 C.-C. Chen and P.-C. Lin, Monitoring of chemical transformations by mass spectrometry, Anal. Methods, 2015, 7, 6947-6959.

${ }^{6}$ P. T. Anastas and J. C. Warner, Green Chemistry: Theory and Practice, Oxford University Press, 1998.

7 D. R. MacFarlane, X. Zhang and M. Kar, Measure and control: molecular management is a key to the Sustainocene!, Green Chem., 2016, 18, 5689-5692.

${ }^{8}$ R. Javanshad and A. R. Venter, Ambient ionization mass spectrometry: real-time, proximal sample processing and ionization, Anal. Methods, 2017, 9, 4896-4907.

9 J. T. Shelley, S. P. Badal, C. Engelhard and H. Hayen, Ambient desorption/ionization mass spectrometry: evolution from rapid qualitative screening to accurate quantification tool, Analytical and Bioanalytical Chemistry, 2018, 410, 4061-4076.

${ }^{10}$ R. B. Cody, J. A. Laramee and H. D. Durst, Versatile new ion source for the analysis of materials in open air under ambient conditions, Anal. Chem., 2005, 77, 2297-2302.

${ }^{11}$ C. Petucci, J. Diffendal, D. Kaufman, B. Mekonnen, G. Terefenko and B. Musselman, Direct Analysis in Real Time for Reaction Monitoring in Drug Discovery, Anal. Chem. 2007, 79, 5064-5070.

12 D. S. Cho, S. C. Gibson, D. Bhandari, M. E. McNally, R. M. Hoffman, K. D. Cook and L. Song, Evaluation of Direct Analysis in Real-Time Mass Spectrometry for Onsite Monitoring of Batch Slurry Reactions, Rapid Commun. Mass Spectrom., 2011, 25, 3575-3580.

${ }^{13}$ A. Ray, T. Bristow, C. Whitmore and J. Mosely, On-line reaction monitoring by mass spectrometry, modern approaches for the analysis of chemical reactions, Mass Spec. Rev., 2018, 37, 565-579.

14 L. P. Harding, G. M. B. Parkes and J. D. Townend, Parameters affecting ion intensities in transmission-mode direct analysis in real-time mass spectrometry, Analyst, 2014, 139, 4176-4180.

${ }^{15}$ G. P. Ashton, L. P. Harding and G. M. B. Parkes, An Integrated Hot-Stage Microscope-Direct Analysis in Real Time-Mass Spectrometry System for Studying the Thermal Behavior of Materials, Anal. Chem., 2017, 89, 13466-13471.

${ }^{16}$ G. P. Ashton, L. P. Harding, G. M. B. Parkes and S. E. Pownall, Application of hot-stage microscopy Direct Analysis in Real-Time mass spectrometry (HDM) to the analysis of polymers, Rapid Commun. Mass Spectrom. 2019, 1-8.

${ }_{17}$ A. A. O. Sarhan and C. Bolm, Iron(iii) chloride in oxidative C-C coupling reactions, Chem. Soc. Rev., 2009, 38, 2730-2744.

18 J. M. Brunel, BINOL: A Versatile Chiral Reagent, Chem. Rev., 2005, 3, 105, 857-897.

$19 \mathrm{~L}$. Meca, D. Reha and Z. Havlas, Racemization barriers of 1,1'-binaphthyl and 1,1'-binaphthalene2,2'-diol: a DFT study, J. Org. Chem., 2003, 68, 14, 5677-5680.

20 S. V. More, M. N. V. Sastry and C.-F. Yao, Cerium (iv) ammonium nitrate (CAN) as a catalyst in tap water: A simple, proficient and green approach for the synthesis of quinoxalines, Green Chem., 2006, 8, 91-95.

${ }^{21} \mathrm{~F}$. Xie, M. Zhang, H. Jiang, M. Chen, W. Lv, A. Zheng and X. Jian, Efficient synthesis of quinoxalines from 2-nitroanilines and vicinal diols via a ruthenium-catalyzed hydrogen transfer strategy, Green Chem., 2015, 79, 279-284.

${ }^{22}$ M. A. Phillips, CCCXVII.-The formation of 2-substituted benziminazoles, J. Chem. Soc., 1928, 23932399.

${ }^{23}$ A. W. Addison and P. J. Burke, Synthesis of some imidazole- and pyrazole- derived chelating agents, J. Heterocyclic Chem., 1981, 18, 803-805.

24 D. Davidson, M. Weiss and M. Jelleing, The action of ammonia on benzil, J. Org. Chem., 1937, 2, 319-327.

${ }^{25} \mathrm{~J}$. V. Alphen, On heterocyclic compounds obtained by: The interactions of benzoins and hydrazine hydrochloride, Recl. Trav. Chim. Pays-Bas., 1933, 52, 47-54.

${ }^{26} \mathrm{~F}$. Toda, K. Tanaka and S. Iwata, Oxidative coupling reactions of phenols with iron(III) chloride in the solid state, J. Org. Chem., 1989, 54, 3007-3009.

${ }^{27}$ B. Wang, P. Li, Y. Zhang and L. Wang, FeCl3-Catalyzed Condensation of 2-Naphthol and Aldehydes under Solvent-Free Reaction Conditions: An Efficient and Green Alternative for the Synthesis of 14Aryl(Alkyl)-14-H-dibenzo[a, j]xanthenes, Chin. J. Chem., 2010, 28, 2463-2468.

28 S. Jana, S. Pande, A. K. Sinha and T. Pal, Synthesis of superparamagnetic MnO2 organosol: a photocatalyst for the oxidative phenol coupling reaction, Inorg. Chem., 2008, 5558-5560.

${ }^{29} \mathrm{~J}$. Doussot, A. Guy and C. Ferroud, Selective synthesis of 1,1'-binaphthalene derivatives by oxidative coupling with TiCl4, Tetrahedron Lett., 2000, 41, 2545-2547. 
${ }_{30}$ M. Shibasaki and S. Matsunaga, Metal/linked-BINOL complexes: Applications in direct catalytic asymmetric Mannich-type reactions, Journal of Organometallic Chemistry, 2006, 691, 2089-2100.

${ }^{31}$ L. Pu, Enantioselective Fluorescent Sensors: A Tale of BINOL, Acc. Chem. Res., 2012, 45, 150-163.

32 B. E. Love and R. A. Bills, FACILE SYNTHESIS OF BINOL IN THE ABSENCE OF SOLVENT, Synthetic Communications, 2002, 32, 2067-2073.

${ }_{33} \mathrm{~S}$. B. Kanungo and S. K. Mishra, Thermal dehydration and decomposition of $\mathrm{FeCl} 3 \cdot \times \mathrm{H} 2 \mathrm{O}$, Journal of Thermal Analysis, 1996, 46, 1487-1500.

${ }^{34} \mathrm{~K} . \mathrm{K} . \mathrm{W}$. Mak, Synthesis and resolution of the atropiomeric 1,1-bi-2-naphthol: An experiment in organic synthesis and 2-D NMR spectroscopy, J. Chem. Educ., 2004, 81, 1636-1640.

35 V. A. Mamedov, Quinoxalines: Synthesis, Reactions, Mechanisms and Structure, Springer International Publishing, Cham, 2016, pp. 5-31.

36 D. Kumar, K. Seth, D. N. Kommi, S. Bhagat and A. K. Chakraborti, Surfactant micelles as microreactors for the synthesis of quinoxalines in water: scope and limitations of surfactant catalysis, RSC Advances, 2013, 15157-15168.

${ }^{37}$ L. Z. Fekri and R. Maleki, KIT-6 Mesoporous Silica-coated Magnetite Nanoparticles: A Highly Efficient and Easily Reusable Catalyst for the Synthesis of Benzo[d]imidazole Derivatives, Journal of Heterocylcic Chemistry, 2017, 54, 1167-1171.

${ }^{38}$ F.K. Behbahani and P. Ziaei, One-pot synthesis of 2-substituted benzimidazoles catalyzed by anhydrous FePO4, Chemistry of Heterocyclic Compounds, 2012, 48, 1011-1017.

${ }^{39}$ M. S. Mohamed, R. A. El-Domany and R. H. Abd El-Hameed, Synthesis of certain pyrrole derivatives as antimicrobial agents, Acta Pharmaceutica, 2009, 59, 145-158.

40 W. B. Leslie and G. W. Watt, The ammonolysis of benzil by liquid ammonia, J. Org. Chem., 1942, 7, 73-78.

${ }^{41}$ M. Hagimori, N. Mizuyama, Y. Tominaga, T. Mukai and H. Saji, A low-molecular-weight fluorescent sensor with $\mathrm{Zn2}+$ dependent bathochromic shift of emission wavelength and its imaging in living cells, Dyes and Pigments, 2015, 113, 205-209. 